\title{
Initiation and Propagation Processes of Internal Fatigue Cracks in $\beta$ Titanium Alloy Based on Fractographic Analysis
}

\author{
Gaoge Xue ${ }^{1}$, Takashi Nakamura ${ }^{1, *}$, Nao Fujimura ${ }^{1}$, Kosuke Takahashi ${ }^{1}$ (D) and Hiroyuki Oguma ${ }^{2}$ (D) \\ 1 Division of Mechanical and Space Engineering, Hokkaido University, Sapporo, Hokkaido 060-8628, Japan; \\ setsu_xue@eis.hokudai.ac.jp (G.X.); fujimura@eng.hokudai.ac.jp (N.F.); ktakahashi@eng.hokudai.ac.jp (K.T.) \\ 2 Research Center for Structural Materials, National Institute for Materials Science, 1-2-1 Sengen, Tsukuba, \\ Ibaraki 305-0047, Japan; OGUMA.Hiroyuki@nims.go.jp \\ * Correspondence: nakamut@eng.hokudai.ac.jp; Tel.: +81-11-706-6419
}

check for updates

Citation: Xue, G.; Nakamura, T.;

Fujimura, N.; Takahashi, K.;

Oguma, H. Initiation and Propagation Processes of Internal Fatigue Cracks in $\beta$ Titanium Alloy Based on Fractographic Analysis. Appl. Sci. 2021, 11, 131. https://dx.doi.org/ 10.3390/app11010131

Received: 1 December 2020 Accepted: 22 December 2020 Published: 25 December 2020

Publisher's Note: MDPI stays neutral with regard to jurisdictional claims in published maps and institutional affiliations.

Copyright: (c) 2020 by the authors. Licensee MDPI, Basel, Switzerland. This article is an open access article distributed under the terms and conditions of the Creative Commons Attribution (CC BY) license (https: / / creativecommons.org/ licenses/by/4.0/).

\begin{abstract}
Uniaxial fatigue tests were conducted for a $\beta$ titanium alloy Ti-22V-4Al up to a very high cycle fatigue (VHCF) regime. The initiation and propagation processes of the internal fatigue cracks were investigated using 3D fractographic analysis. Multiple facets were observed at the crack initiation site. Three facet initiation models were proposed based on the surface appearances and the 3D facet bonding patterns of the multiple facets, and the major facet was determined to be the true crack initiation site. Using the size of the major facet, a Tanaka-Akiniwa model, which can determine the material constants for the Paris law using only conventional fatigue tests, was applied to reveal the propagation process of the internal cracks. A reverse fatigue life prediction was also conducted to evaluate the accuracy of the material constants obtained using the Tanaka-Akiniwa model. When the facet initiation models were applied, the predictions showed less deviation and better agreement than when the facet initiation process was not considered. The findings of this study indicate that the formation of multiple facets in $\beta$ titanium alloys is sequential rather than simultaneous.
\end{abstract}

Keywords: internal fracture; facet; crack initiation; very high cycle fatigue

\section{Introduction}

Titanium and its alloys are widely used as aerospace materials owing to their excellent mechanical properties, particularly, their fatigue resistance. $\beta$ titanium alloy has emerged as a promising titanium alloy and has been used in recent years in several landing gear systems in aircrafts such as Boeing 787 and Airbus A380 [1-4].

Generally, it is considered that when the applied stress is less than the fatigue limit, the alloy material exhibits an infinite fatigue life. In the past two decades, however, the occurrence of a fatigue fracture originating from inside the alloy material below the conventional fatigue limit has been reported in a very high cycle fatigue (VHCF) regime $[5,6]$. Therefore, tremendous efforts have been devoted by several researchers to investigate the fatigue behavior of $\beta$ titanium alloys and these studies have confirmed the occurrence of internal fractures in the VHCF regime [7-11].

The propagation rate of the internal crack is commonly used to describe the crack behavior in the VHCF regime. However, the direct observation of the internal crack is extremely difficult. Consequently, several researchers have devoted considerable efforts to develop indirect approaches for obtaining the internal crack propagation rate. For example, Tanaka et al. used a conventional fatigue test and fractography to obtain the crack propagation rate of a high-strength steel [12]. In addition, Furuya et al. developed fractographic models for estimating the fatigue life of steel in the VHCF regime [13,14]. The most important step of these methods was to clearly determine the crack initiation area. However, these attempts have not successfully conducted on titanium alloys. Shiozawa et al. estimated the fatigue life of Ti-15V-3Cr-3Sn-3Al using fractography and reported that there was a large deviation in internal fractures [15]. One of the reasons for this is, compared 
with inclusions which are the internal crack initiation sites of steels, it is more difficult to determine and identify multiple facets, which are commonly observed at the internal crack initiation sites of titanium alloys [15-17]. In addition, at the early stage of the internal crack propagation process, the facet initiation and crack propagation behavior are strongly affected by several factors such as microstructures and grain orientation, which cause a significant deviation in the fatigue life estimation of internal cracks. This indicates that it is important to develop a general model that can illustrate the facet initiation and propagation behavior of titanium alloys.

In this study, we investigated the multiple facets growth (initiation and propagation) process of a $\beta$ titanium alloy by fractography and applying the Tanaka-Akiniwa model [12] to derive the material constants for the Paris law and the propagation rate of internal cracks. Finally, a reverse fatigue life estimation was conducted to evaluate the accuracy of the obtained material constants.

\section{Fatigue Test Conditions and Results}

\subsection{Test Material and Fatigue Test Conditions}

The material used in this study was a metastable $\beta$ titanium alloy Ti-22V-4Al (Material code DAT51 [18]), and the chemical composition of this alloy is listed in Table 1. The asreceived materials were $\Phi 18 \mathrm{~mm} \times 250 \mathrm{~mm}$ round bars. Fukui et al. investigated the effect of heat treatment conditions on the mechanical properties of this alloy [19]. Based on their results, we conducted experiments to obtain a good balance between tensile strength and elongation. The optimal heat treatment process for the as-received materials was determined to be as follows: solution treatment at $1023 \mathrm{~K}$ for $1 \mathrm{~h}$ followed by water quenching, and aging at $823 \mathrm{~K}$ for $4 \mathrm{~h}$ followed by air cooling. The heating process of solution treatment and aging were carried out as follows: first, the bars were set into an ambient temperature furnace and then heated gradually to the target temperature at a heating rate of $50 \mathrm{~K} / \mathrm{h}$ to obtain a homogenous and fine $\alpha$-phase precipitation in the $\beta$ grain, as shown in Figure 1. The average grain size of the heat-treated material was approximately $20 \mu \mathrm{m}$. The mechanical properties, which are the average values from three tests, are listed in Table 2 . The tensile strength $(1235 \mathrm{MPa})$ is higher than that of widely used $\alpha+\beta$ titanium alloys, which exhibits around 900 to $1100 \mathrm{MPa}$. In addition, the ductility (Elongation: 9.3\%, Reduction of Area: $21.9 \%$ ) provides an excellent workability. The specimens used for the fatigue test had an hourglass configuration with a 4-mm diameter and 6-mm straight length of the control volume. To diminish the influence of the work-hardened layer caused by the lathe turning process, the specimen surface was finished by polishing with \#120 to \#2000 emery papers.

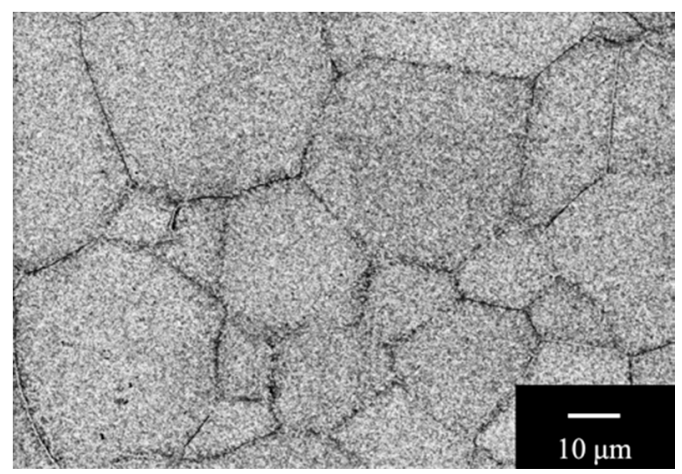

(a)

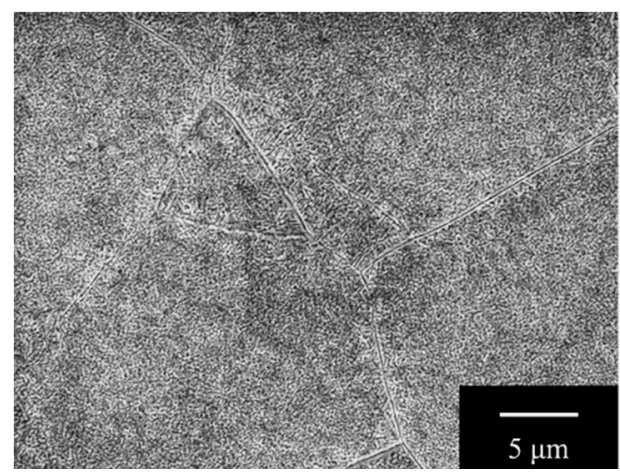

(b)

Figure 1. Microstructure of the applied Ti-22V-4Al alloy with a homogenous and fine $\alpha$-phase precipitation from SEM analysis: (a) low-magnification and (b) high-magnification images. The material was polished to a mirror finish and then etched with Kroll's reagent $\left(\mathrm{HF}: \mathrm{HNO}_{3}: \mathrm{H}_{2} \mathrm{O}=1: 2: 50\right)$ for 8-10 s. 
Table 1. Chemical composition of the Ti-22V-4Al (mass \%).

\begin{tabular}{cccccccc}
\hline $\mathbf{A l}$ & $\mathbf{V}$ & $\mathbf{F e}$ & $\mathbf{C}$ & $\mathbf{O}$ & $\mathbf{N}$ & $\mathbf{H}$ & $\mathbf{T i}$ \\
\hline 4.15 & 21.17 & 0.15 & 0.013 & 0.14 & 0.012 & 0.0124 & Bal. \\
\hline
\end{tabular}

Table 2. Mechanical properties of the applied Ti-22V-4Al alloy.

\begin{tabular}{cccc}
\hline $\begin{array}{c}\mathbf{0 . 2} \% \text { Proof Stress } \\
{[\mathrm{MPa}]}\end{array}$ & $\begin{array}{c}\text { Tensile Strength } \\
{[\mathrm{MPa}]}\end{array}$ & $\begin{array}{c}\text { Elongation } \\
{[\%]}\end{array}$ & $\begin{array}{c}\text { Reduction of Area } \\
{[\%]}\end{array}$ \\
\hline 1154 & 1235 & 9.3 & 21.9 \\
\hline
\end{tabular}

A uniaxial hydraulic servo fatigue testing machine developed in our laboratory was used to provide a sinusoidal loading of $120 \mathrm{~Hz}$. Three stress ratios $(R=$ minimum stress/maximum stress) were chosen for fatigue tests $(R=-1 ; R=-0.5 ; R=0.1)$, and the experimental run-out was set at $10^{8}$ cycles.

\subsection{Fatigue Test Results}

Figure 2 shows the relationships between the maximum applied stress $\left(\sigma_{\max }\right)$ and the number of cycles to fracture $\left(N_{\mathrm{f}}\right)$ for the different stress ratios ( $S-N$ curves). When $R=-1$, the $S-N$ curve exhibited a step-wise (or duplex) shape. In addition, the gradient of the $S-N$ curve changed twice (the changing point is hereafter referred to as the "transition point"). First, the fracture mode of the specimens was a surface fracture mode in the high stress regime, and the first transition point occurred at approximately $5 \times 10^{4}$ cycles. Then, a region in which surface fracture does not occur, which represents the fatigue limit of surface fracture, lasted until $2 \times 10^{7}$ cycles, which is regarded as the second transition point. After the second transition point, the fracture mode of the specimens changed into an internal fracture. Similarly, when $R=-0.5$, the $S-N$ curve of the specimens exhibited a step-wise shape. In addition, the first transition point at $R=-0.5$ occurred at a similar cycle as $R=-1$. However, the second transition point characterized by internal fracture appeared earlier than that of $R=-1$. In contrast to $R=-1$ and $R=-0.5$, when $R=0.1$, only one surface fracture was obtained. In addition, it was difficult to accurately determine the first transition point when $R=0.1$. However, the second transition point at $R=0.1$ appeared earlier than those of the other stress ratios, and the shape of the $S-N$ curve was close to asymptotic under $R=0.1$. The loading cycles between the first and second transition points reduced with an increase in stress ratios. The reason for evolution of the $S-N$ shape of the $\beta$ titanium alloy is not yet properly understood. However, these observations are consistent with the findings of Shiozawa et al., indicating that the trend in Figure 2 is a common fatigue characteristic of $\beta$-titanium alloys [15]. 




Figure 2. Relationship between the maximum applied stress and the number of cycles to fracture for different stress ratios. A step-wise shape is observed for the stress ratios $R=-1$ and $R=-0.5$, but an asymptotic shape is observed for $R=0.1$.

\section{Fractography}

\subsection{Condition of Fracture Surface Observation}

The fracture surface features of the specimens were observed by scanning electron microscopy (SEM) with 3D analysis functions (Keyence VK-9800). The 3D images were created using two SEM images of the same position and magnification: one was taken by tilting the sample stage at $5^{\circ}$ and the other was taken without tilting. The resolution of the 3D images was approximately $100 \mathrm{~nm} /$ pixel so that it can reflect the fracture surface on a micrometer scale. The obtained SEM images were analyzed with the ImageJ image processing program [20]. Particular attention was paid to the features of the internal crack initiation site.

\subsection{Fracture Surface Characteristics}

Figure 3 shows the surface and internal fracture images of the test specimens. A fatigue crack was initiated from the matrix, and no inclusion or void was observed at the fracture origin in each specimen regardless of the stress ratios. In addition, radial patterns, which were initiated from the crack initiation site, were confirmed on the fracture surfaces [11,15,21,22].

A crystallographic tiny flat site, known as a facet, was observed at the crack initiation site in all cases. Additionally, multiple facets were observed in most cases (14-16). Unlike the dispersive characteristic of Ti-6Al-4V $[23,24]$, the multiple facets in Ti-22V-4Al were connected to each other to form a whole structure. These facet characteristics of $\beta$ titanium alloys are consistent with the reports of previous studies $[8,9,15,25,26]$.

\subsection{Facet Angle Statistics}

Figure 4 shows the schematic of facet angle measurement. The facet angle $\theta$ was calculated from the arc tangent of the vertical height and horizontal length. A total of 41 facets were measured, and the measured angles were plotted into a normal distribution paper regardless of the fracture mode, as shown in Figure 5. The cumulative probability was calculated using Equation (1):

$$
F_{i}\left(\theta_{i}\right)=i /(n+1)(i=1,2, \ldots, 41),
$$

where $F_{i}$ is the cumulative probability, $\theta_{i}$ is the angle of facet, and $n$ is the sample's capacity, which is 41 in this equation. The plots in the normal distribution probability paper showed a clear linear relationship, indicating that the measured facet angles strongly obey a normal distribution $\left(R^{2}=98.99 \%\right)$. In addition, the average value of the facet angle was $44.7^{\circ}$ with a standard deviation of $5.4^{\circ}$, which indicates that slip dislocation was the dominant mechanism for the facet formation. 


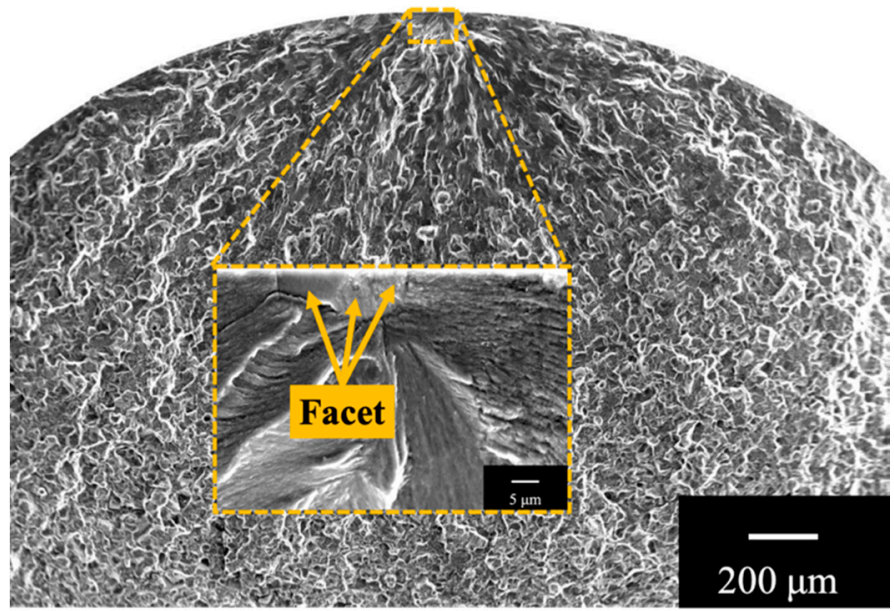

(a)

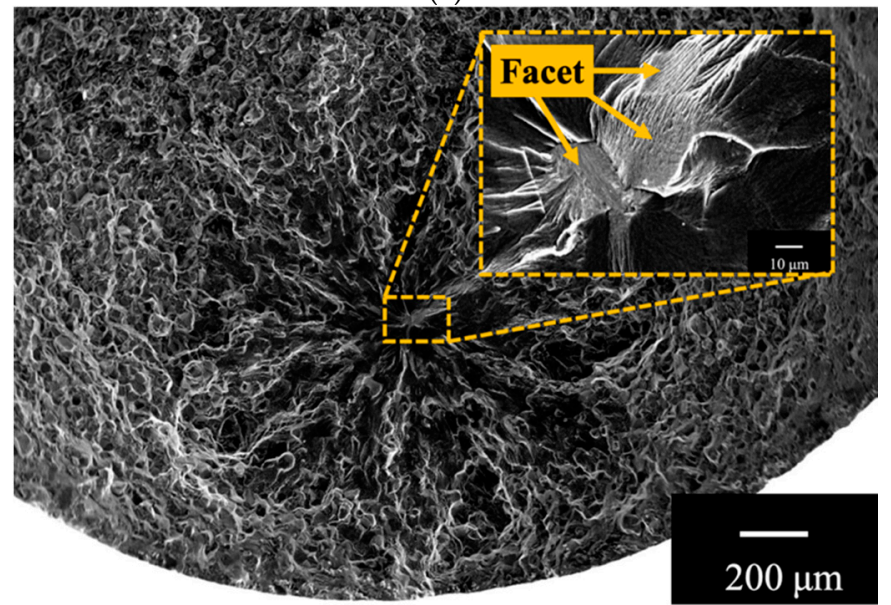

(b)

Figure 3. SEM images of the fracture surface. (a) Surface fracture, $\sigma_{\text {max }}=700 \mathrm{MPa}, R=-1$, $N_{\mathrm{f}}=3.5 \times 10^{4} ;(\mathbf{b})$ Internal fracture, $\sigma_{\max }=975 \mathrm{MPa}, R=0.1, N_{\mathrm{f}}=4.5 \times 10^{6}$.



Figure 4. Schematic of the facet angle measurement. 




Figure 5. Facet angles plotted on a probability paper of normal distribution.

\subsection{Facet Surface Features of the Internal Fracture}

\subsubsection{Positive Stress Ratio}

Figure 6 shows the 2D-SEM images of multiple facets of the internal fracture under a positive stress ratio. The observed facets were classified into two types based on their surface features: First, facets with smooth surfaces, which were observed in all specimens. The other facet type was randomly distributed facets with obvious striped tracks on their surfaces. These results indicated that the facets with smooth surfaces were the crackinitiating facets. Therefore, in this study, to describe the role of various facets in the crack initiation process, the facet with smooth surfaces were defined as the "major facet," and the facet with striped tracks were defined as the "minor facet".

Based on the facet boundaries, the major facet had a relatively clearer grain-shaped boundary compared with the minor facet. This phenomenon can be attributed to the restrain of the grain boundary. Because the first facet is formed inside a grain, the slip band in the first facet formation was smaller than the grain size. Tanaka et al., Lankford et al., and Zhai et al. reported the that the grain boundary blocking effect on slip bands is significant when the length of the slip band is on or below the order of the grain size [27-29]. This suggested that the major facet was the first generated facet, and that the grain boundary blocking effect played a significant role during the major facet formation process. However, as the crack propagation proceeded, the length of the slip band during the minor facet formation increased, thus diminishing the blocking effect of the grain boundary. This was further confirmed by the unclear boundary of the minor facet(s). 


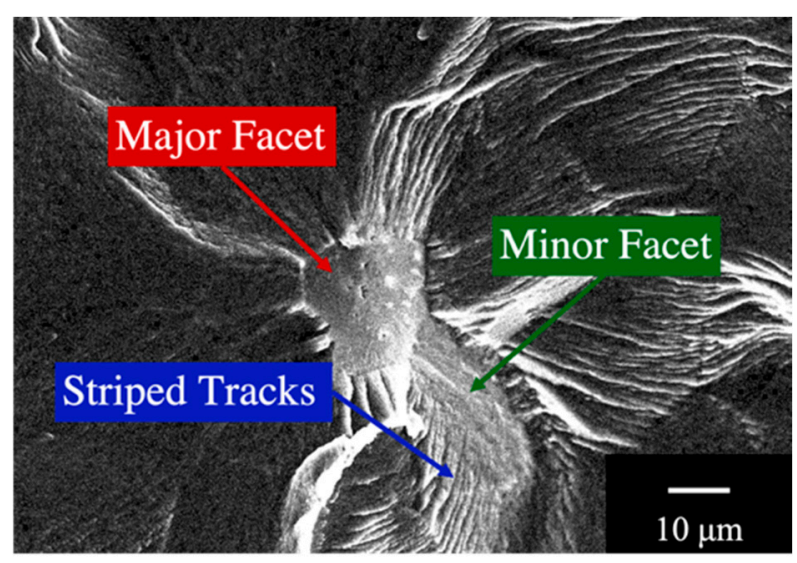

(a)



(b)

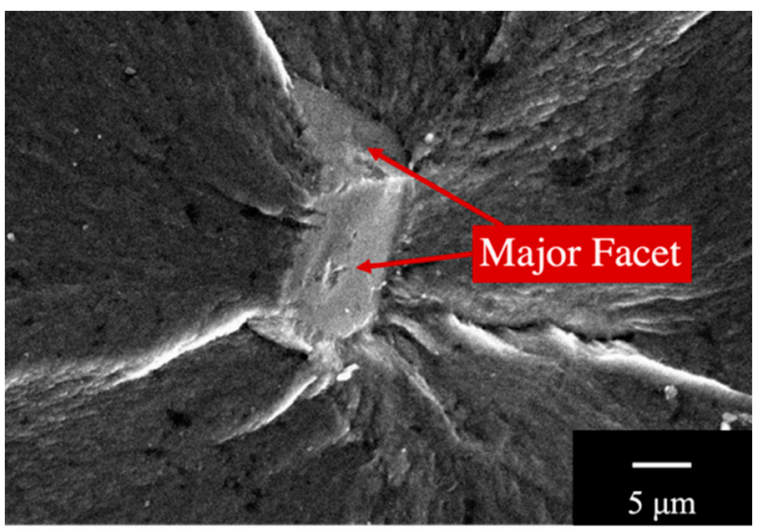

(c)

Figure 6. SEM images of the multiple facets under positive stress ratio. (a) $\sigma_{\max }=1125 \mathrm{MPa}, R=0.1, N_{\mathrm{f}}=6.5 \times 10^{4}$; (b) $\sigma_{\max }=975 \mathrm{MPa}, R=0.1, N_{\mathrm{f}}=4.5 \times 10^{6} ;$ (c) $\sigma_{\max }=1000 \mathrm{MPa}, R=0.1, N_{\mathrm{f}}=3.0 \times 10^{5}$.

\subsubsection{Negative Stress Ratios}

Figure 7 shows the 2D-SEM images of the multiple facets of the internal fracture under negative stress ratios. Similar to the fractographic results obtained under positive stress ratio, major facet(s) with a smooth surface and clear grain-shaped boundary, and minor facet(s) with striped tracks were observed. However, compared with the striped tracks of the minor facet surfaces under positive stress ratios (Figure 6a,b), those under negative stress ratios were less remarkable (Figure 7). This phenomenon can be explained by the fact that the striped tracks on the facet surfaces were already completely formed during the formation of the minor facets before the propagation of the crack outside the multiple facets. However, they were subsequently diminished by the compressive process under a negative stress ratio. This provides insights on the different formation processes of the major and minor facet(s). 


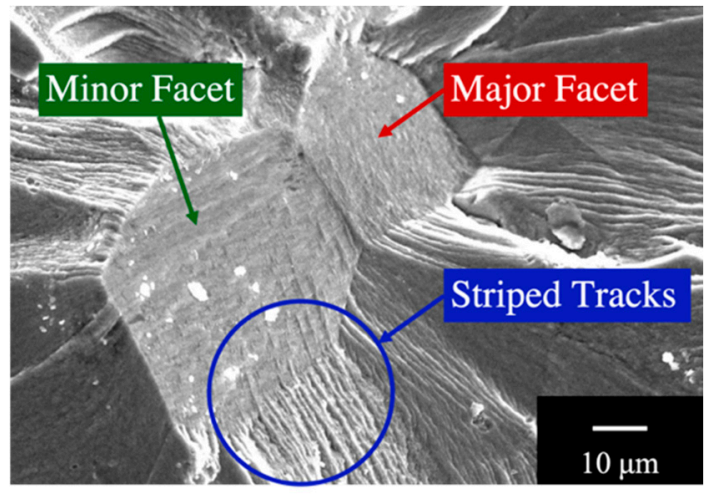

(a)

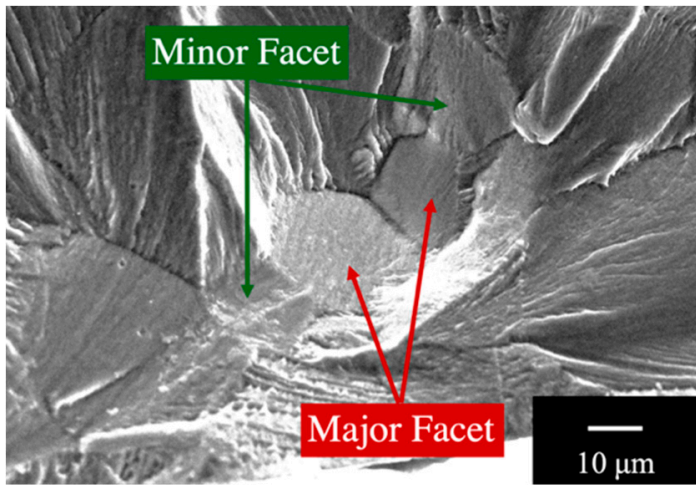

(b)

Figure 7. SEM images of the multiple facets under negative stress ratios. (a) $\sigma_{\max }=800 \mathrm{MPa}, R=-0.5, N_{\mathrm{f}}=4.7 \times 10^{6}$; (b) $\sigma_{\max }=625 \mathrm{MPa}, R=-1, N_{\mathrm{f}}=2.0 \times 10^{7}$.

In summary, multiple facets that approached $45^{\circ}$ were observed at the fracture initiation site regardless of the stress ratios and fracture mode (i.e., surface fracture and internal fracture), and were classified into the major facet(s) and the minor facet(s) based on their surface appearances. The surface characteristics of the major and minor facet(s) are shown in Table 3. The major facet(s), which were observed in all specimens, had a relatively clear boundary and smooth surface. In contrast, the surface of the randomly distributed minor facet(s) had striped tracks. The stress ratios had a significant effect on the striped tracks of the minor facets, but had no significant effect on the surface of the major facet, indicating that the smooth surface of the major facet was not formed by the compressive process but by its own initiation process. These fractography results indicate that the formation process of the major and minor facets was dissimilar. In the next section, the facet bonding pattern of the facets was discussed to describe the various facet initiation processes.

Table 3. Characteristics of the major and minor facet.

\begin{tabular}{cccc}
\hline & Surface Feature & Boundary & \multicolumn{2}{c}{ Distribution in Every Specimen } \\
\hline The major facet & Smooth & Clear & At least one \\
\hline \multirow{2}{*}{ The minor facet } & Striped Tracks; & Unclear & Random \\
\hline
\end{tabular}

\subsection{Facet Bonding Patterns}

As mentioned in Section 3.3, although all facets were likely formed by slip dislocation, the sequences of their formation were different. Therefore, we classified the relationship of normal vectors on various facets via 3D fractography to reveal the interaction between the major and minor facets.

\subsubsection{Slope Type}

Some of the specimens showed a pattern wherein the normal vectors of the facets were parallel to each other. This pattern can be defined as the "slope type." Based on the altitude relations between the major and minor facet(s), the slope types can be further sub-classified into the vertical slope type (Figure 8) and the horizontal slope type (Figure 9). The slip system of the minor facet(s) could easily be activated by the crack tip stress concentration after the major facet initiation, indicating that the slope type exhibited a two-step facet growth behavior. 


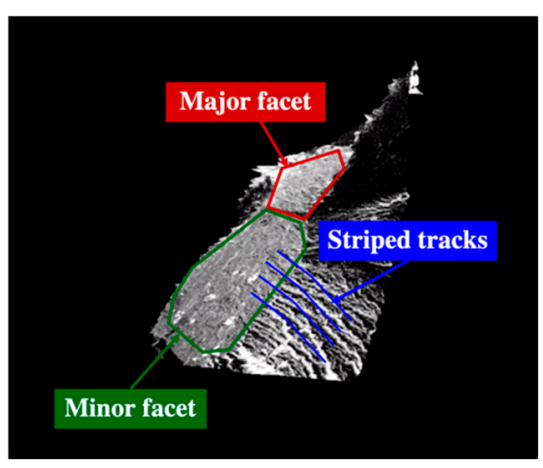

(a)

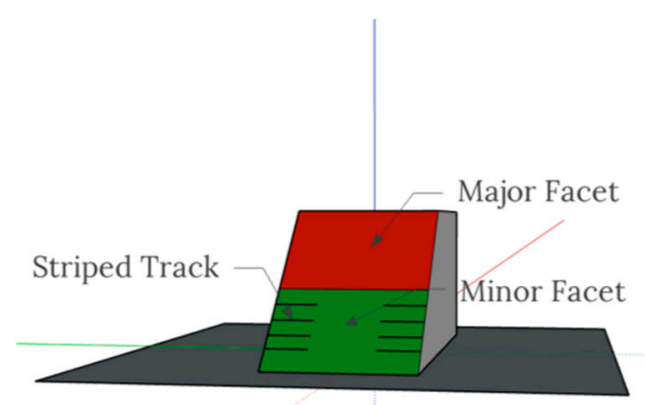

(b)

Figure 8. Example of the vertical slope type. These facets are the same facets shown in Figure $7 \mathrm{a}\left(\sigma_{\max }=800 \mathrm{MPa}, R=-0.5\right.$, $N_{\mathrm{f}}=4.7 \times 10^{6}$ ). (a) 3D-SEM image; (b) 3D-model schematic image.



(a)

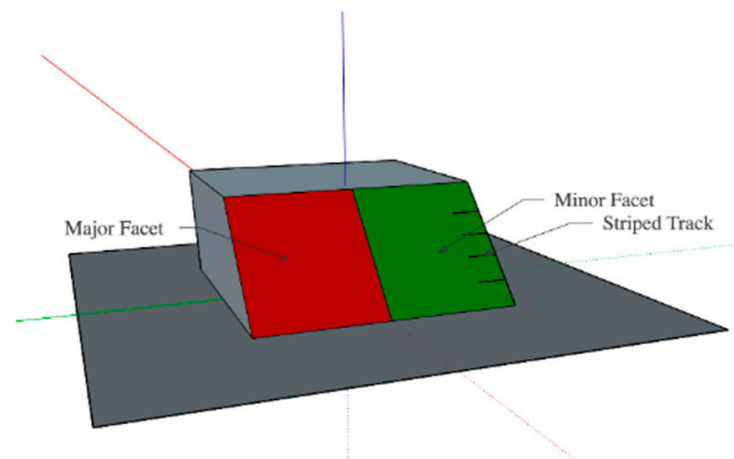

(b)

Figure 9. Example of the horizontal slope type. These facets are the same facets shown in Figure $6 \mathrm{~b}\left(\sigma_{\max }=975 \mathrm{MPa}\right.$, mboxemphR $\left.=0.1, N_{\mathrm{f}}=4.5 \times 10^{6}\right)$. (a) 3D-SEM image; (b) 3D-model schematic image.

\subsubsection{Peak Type}

The specimens exhibited a pattern in which the normal vectors of the facets were pointing in different directions, as shown in Figure 10. This pattern can be defined as the "peak type" and it indicates that it is difficult to activate one facet slip system using another one, and as thus, the two bonding facets were formed simultaneously. This consideration is consistent with the definition of major facets, as mentioned in Section 3.4.1.

\subsubsection{Combination Type}

The combination of the two bonding types was also observed in some specimens and was defined as the "combination type (Figure 11)." The top two facets were selected as the major facets due to the different orientations of normal vectors (i.e., peak type), and the pattern with bottom minor facets connecting the major facets was considered as the slope type. 


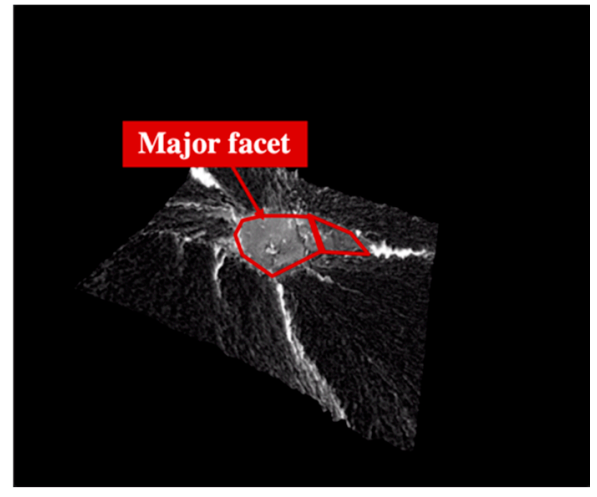

(a)



(b)

Figure 10. Example of the peak type. These facets are the same facets shown in Figure $6 \mathrm{c}\left(\sigma_{\max }=1000 \mathrm{MPa}, R=0.1\right.$, $N_{\mathrm{f}}=3.0 \times 10^{5}$ ). (a) 3D-SEM image; (b) 3D-model schematic image.

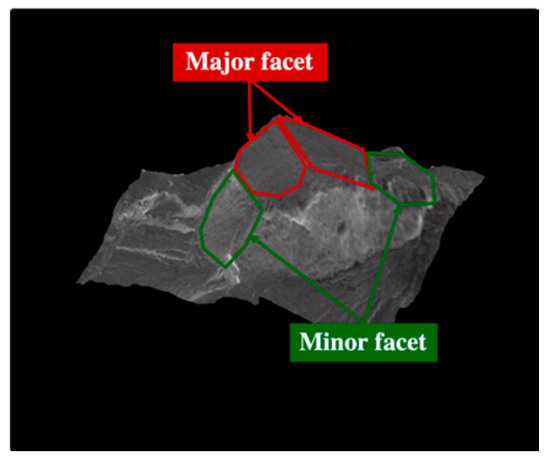

(a)

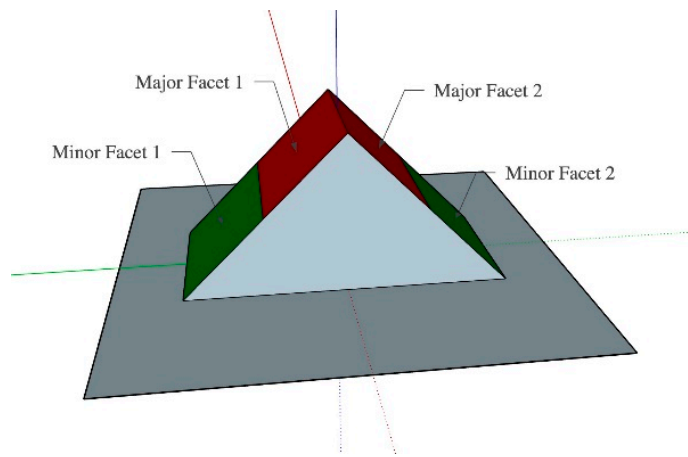

(b)

Figure 11. Example of the combination type. These facets are the same facets shown in Figure $7 \mathrm{~b}\left(\sigma_{\max }=625 \mathrm{MPa}, R=-1\right.$, $N_{\mathrm{f}}=2.0 \times 10^{7}$ ). (a) 3D-SEM image; (b) 3D-model schematic image.

\section{Discussion}

\subsection{Derivation of the Material Constants in Paris Law Based on the Tanaka-Akiniwa Model}

To verify the accuracy of the facet initiation and propagation of the facet patterns established in Section 3., the Paris law was employed, as shown in Equation (2) [30].

$$
\frac{d a}{d N}=C(\Delta K)^{m}
$$

where $C$ and $m$ are material constants used to describe crack behavior in terms of the crack propagation rate. By integrating the Paris law from the initial crack length to infinity, a linear relationship between the initial stress intensity factor range $\left(\Delta K_{i n i}\right)$ and the value of crack propagation life over initial crack length $\left(N_{\text {propa }} / a_{\text {ini }}\right)$ can be exhibited in a double logarithmic chart. This relationship shown in Equation (3) is called the Tanaka-Akiniwa model or the $\Delta K_{\text {ini }}-N_{\text {propa }} / a_{\text {ini }}$ diagram [12,31].

$$
\log \left(\Delta K_{\text {ini }}\right)=-\frac{1}{m} \log \left(\frac{N_{\text {propa }}}{a_{\text {ini }}}\right)+\frac{1}{m} \log \left[\frac{2}{C(m-2)}\right]
$$

The gradient of the $\Delta K_{i n i}-N_{\text {propa }} / a_{i n i}$ diagram was used to obtain the exponential material constant, $m$, and the coefficient material constant, $C$, was calculated by substituting $m$ into the intercept. Considering that the fatigue crack in the $\beta$ titanium alloys was initiated from the facet, $a_{i n i}$ was replaced by the root of the facet area projected on the fracture surface, 
$\sqrt{\operatorname{area}_{\text {ini }}}$, which can be measured by fractography. In addition, the experimental fatigue life, $N_{e}$, was substituted for $N_{\text {propa }}$. This indicates that the crack physically propagated from a chosen facet throughout the entire fatigue life. In other words, the crack initiation life and facet formation life were omitted. The effect of the crack initiation life and facet formation life on this calculation will be discussed in Section 4.3. Using the above steps, Equation (3) evolved into Equation (4), which is appropriate for the present work:

$$
\log \left(\Delta K_{i n i}\right)=-\frac{1}{m} \log \left(\frac{N_{e}}{\sqrt{\text { area }_{i n i}}}\right)+\frac{1}{m} \log \left[\frac{2}{C(m-2)}\right]
$$

where $\Delta K_{\text {ini }}$ can be calculated using the following Murakami formulas [32] in Equations (5) and (6):

$$
\begin{aligned}
& \text { Surface crack : } \Delta K_{i n i}=0.65 \Delta \sigma \sqrt{\pi \sqrt{\text { area }_{\text {ini }}}} \\
& \text { Internal crack : } \Delta K_{i n i}=0.5 \Delta \sigma \sqrt{\pi \sqrt{\text { area }_{\text {ini }}}}
\end{aligned}
$$

where $\Delta \sigma$ is the range of the applied stress. For the negative stress ratios, $\Delta \sigma$ represents the positive parts of the applied stress (i.e., from zero to the maximum applied tensile stress).

In previous studies, the multiple facets were not properly distinguished [15]. Therefore, in this study, as a no-treatment control group, not only the major facet(s) area, but also the total facet area (i.e., the whole area of multiple facets) was applied to determine the crack initiation site area, $\left(\sqrt{\text { area }_{\text {ini }}}\right)$. Figure $12 \mathrm{a}, \mathrm{b}$ shows the $\Delta K_{\text {ini }}-N_{e} / \sqrt{\text { area }_{\text {ini }}}$, in which the total facet area and major facet(s) area were applied, respectively. The $N_{e}$ values were obtained from the $S-N$ curve in Figure 2. The linear relationship was calculated using the least squares method. The data were plotted separately in terms of fracture mode (i.e., surface fracture and internal fracture) and can be clearly distinguished. In both cases when the total facet area and the major facets area were applied, a larger $m$ and a smaller $C$ were derived for the internal fracture mode compared with that of surface fracture. The relatively large value of $m$ but smaller $C$ of the internal fracture regime has been reported in several studies [12-14]. In addition, the effects of the stress ratio on the $S-N$ curve were almost diminished for both surface and internal fracture.

In the plot of the internal fracture mode, when the total facet area was used, the plots were very scattered, and as thus, the material constants might not be accurately acquired. However, when the major facet area was used, the plots showed less deviation and a better linear relationship, indicating that the major facet(s) is appropriate for determining the real initiation site of the internal cracks. These observations indicate that the facets of the internal cracks follow two-step facet initiation and propagation behaviors.

In contrast, in the surface fracture regime, both the total facet area and the major facet area showed acceptable plot distribution and linear relationship for calculating the material constants. That can be explained as follows: The coefficient material constant $C$ was 10-20 orders larger in the surface fracture regime than in the internal fracture regime. This indicates that the crack propagation rate of the surface fracture was much faster than that of the internal fracture. Consequently, the high surface propagation rate enabled the propagation of the crack through a grain and overcame the restraints of the microstructural effect, which in turn makes the determination of the crack initiation sites less important or even negligible. 


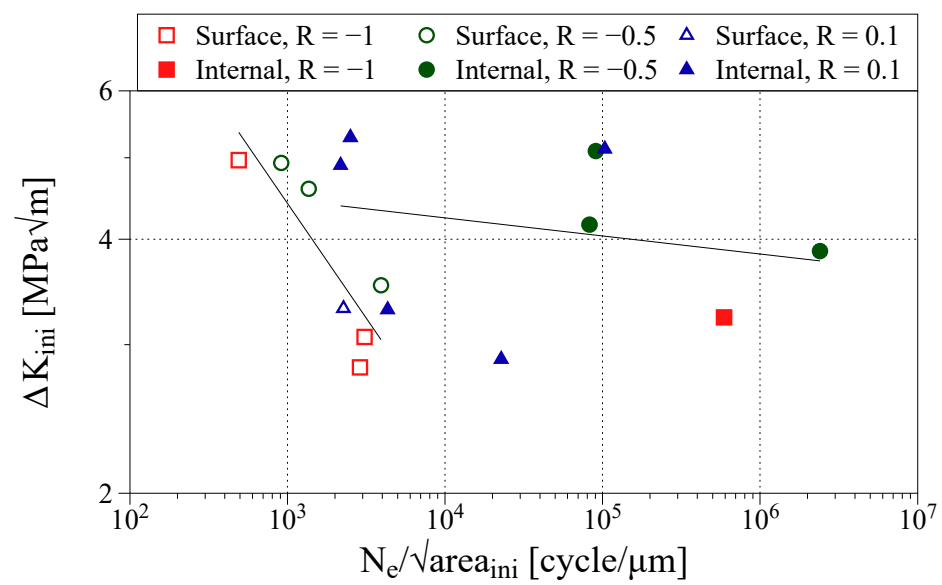

(a)

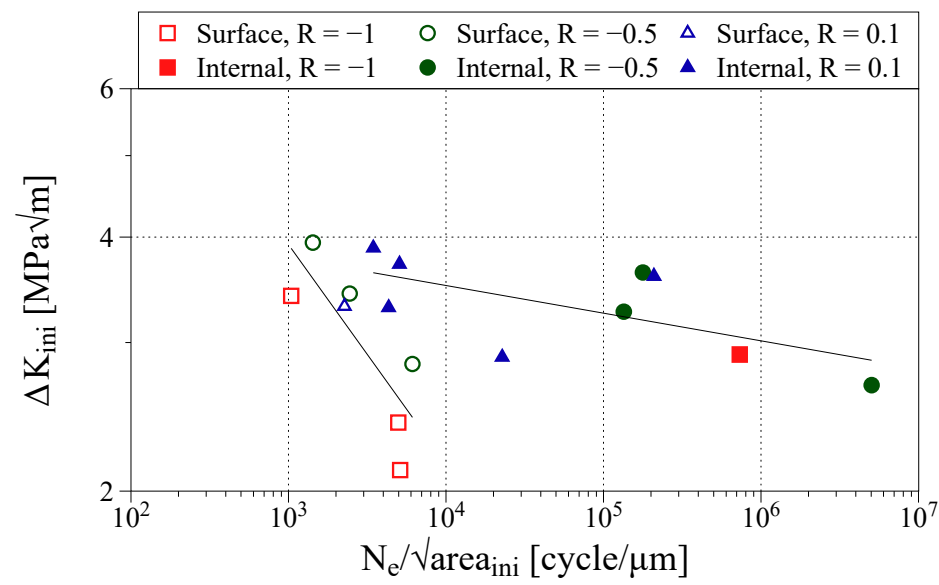

(b)

Figure 12. $\Delta K_{i n i}-N_{e} / \sqrt{\text { area }_{i n i}}$ diagrams. (a) Total facets area (surface: $C=5.04 \times 10^{-9}, m=3.68$; internal: $\left.C=2.1 \times 10^{-38}, m=46.7\right)$; (b) Major facet(s) area (surface: $C=5.76 \times 10^{-9}, m=3.84$; internal: $C=1.72 \times 10^{-25}, m=30.5$ ).

\subsection{Fatigue Life Prediction}

Fatigue life prediction was carried out to evaluate the validity of the obtained results from another point of view. By the reverse calculation of Equation (4), the fatigue life prediction equation was derived, as shown in Equation (7):

$$
N_{p}=\frac{2 \sqrt{\operatorname{area}_{\text {ini }}}}{\left(\Delta K_{\text {ini }}\right)^{m} C(m-2)}
$$

where $N_{p}$ is the predicted fatigue life, $C$ and $m$ are the material constants derived from the $\Delta K_{i n i}-N_{e} / \sqrt{\operatorname{area}_{i n i}}$ diagram in Figure 12. To evaluate the accuracy of the prediction, the ratio of the predicted fatigue life to the experimental fatigue life $\left(N_{p} / N_{e}\right)$ was calculated. The closer this ratio is to 1 , the better the accuracy of prediction obtained. Figure 13a,b show the prediction results using the total facet area and the major facet(s) area, respectively. The stress ratio had no significant effect on the fatigue properties. 


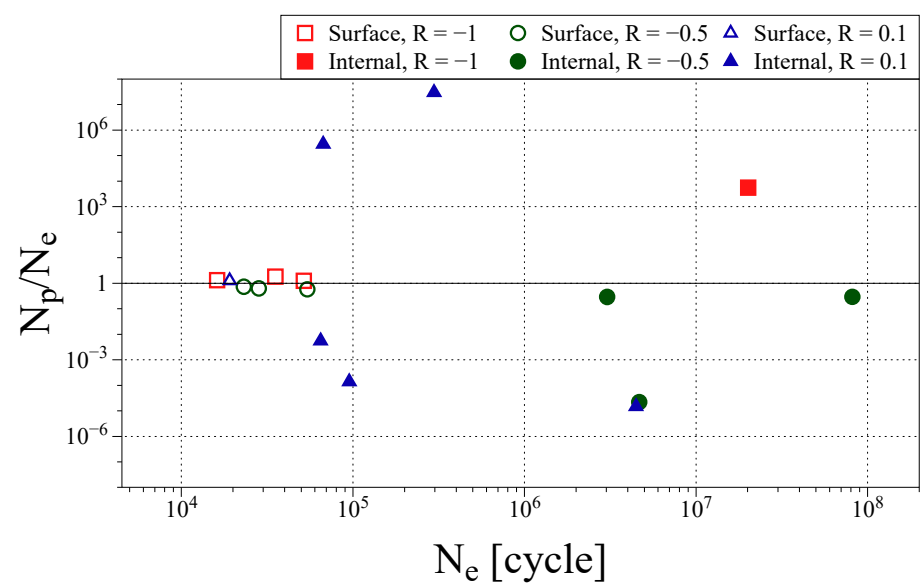

(a)



(b)

Figure 13. Relationship between the predicted and experimental fatigue life $\left(N_{p} / N_{e}\right)$. (a) Using total facets area; (b) Using major facet area.

In addition, a similar feature to that of the $\Delta K_{i n i}-N_{e} / \sqrt{\operatorname{area}_{i n i}}$ diagrams in Section 4.1. was observed. For the surface fracture regime, the total facet area and major facet(s) area exhibited great prediction accuracy. In contrast, the $N_{p} / N_{e}$ range of the internal fracture regime decreased sharply when the major facet area was used than when the total facet area was used. These results also confirm the reliability of the two-step facet initiation and propagation process.

\subsection{Effect of the Crack Initiation Life and Facet Formation Life on the Derivation Process of the} Material Constants

In general, fatigue life can be divided into the crack initiation life and crack propagation life. In facet-originated fractures, the crack initiation life represents the number of loading cycles before the first facet formation. The crack propagation life can be sub-divided into the facet formation life and the loading cycles consumed after the facet formation, respectively. Considering the two-step facet growth behavior, the schematic of the fatigue process in the $\beta$ titanium alloy is shown in Figure 14. In Section 4.1., the experimental fatigue life was applied to derive the material constants (i.e., the crack initiation life and facet formation life were not considered in the calculation). Yoshinaka et al. conducted $X$-ray computed tomography (CT) to observe the internal fractures in an $\alpha+\beta$ titanium alloy Ti-6Al-4V. They reported that the crack initiation life varied from $20 \%$ to $80 \%$ of the total fatigue life, and that the first facet was formed instantaneously [33]. This indicates that the first facet formation life (i.e., fatigue life consumed by the major facet formation in the present study) is negligible. However, the crack initiation life should be considered for 
the estimation of the crack propagation rate. Therefore, in this section, we paid particular attention to the effect of the crack initiation life on the derivation process of the material constants based on the Tanaka-Akiniwa model.

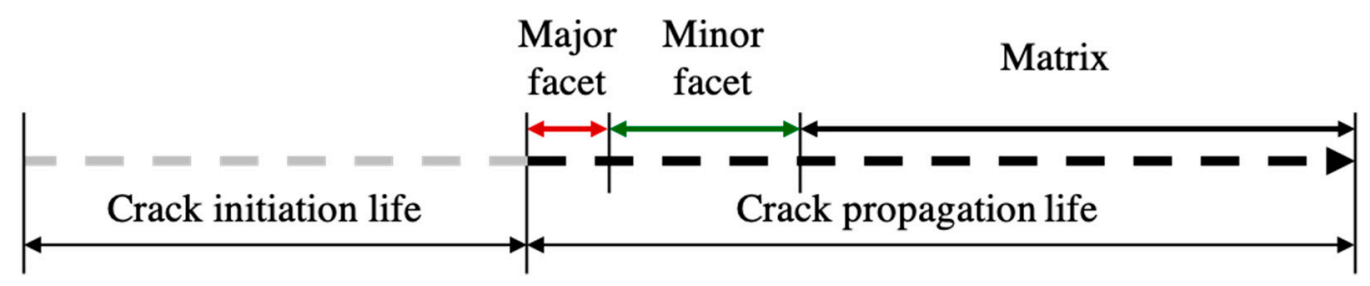

Figure 14. Fatigue life classification.

Figure 15 shows the relationship between the crack propagation rate and stress intensity factor range ( $d a / d N-\Delta K$ curves) obtained using the material constants from the major facet(s). To illustrate the effect of the crack initiation life, three cases were chosen as examples. The first case was obtaining the $d a / d N-\Delta K$ curve without considering the initiation life. In the second and third cases, the crack initiation life occupied $70 \%$ and $90 \%$ of the fatigue life, respectively (i.e., 30\% experimental fatigue life $\left(N_{e}\right)$ and $10 \% N_{e}$ were applied to Equation (4), respectively, instead of $N_{e}$ ). With an increase in the crack initiation life, the derived crack propagation rate increased.



Figure 15. Relationship between crack propagation rate and stress intensity factor range derived from the Tanaka-Akiniwa model in terms of fracture mode and crack initiation life.

For the surface fracture regime, Tokaji et al. measured the crack propagation rate of a Ti-22V-4Al alloy subjected to heat treatment (solution treatment at $1023 \mathrm{~K}$ for $1 \mathrm{~h}$ and aging at $723 \mathrm{~K}$ for $8 \mathrm{~h}$ ) under similar conditions as those used in this study. A linear regression of the data reported in their study was also plotted with a dashed line in Figure 15. Although the slope of the line was slightly smaller than that of the $0 \%, 70 \%$, and $90 \%$ initiation life, the order of the crack propagation rate was consistent with that of this study. In addition, they reported that the crack initiation life was $70-80 \%$ of the experimental fatigue life $[8,25]$. 
Based on this report and the fact that the dashed line was located around the $70 \%$ initiation life, the surface crack initiation life in this study was considered approximately $70 \%$ of the fatigue life. This indicates that the Tanaka-Akiniwa model is suitable for deriving the material constants of surface cracks with a particular crack initiation life in $\beta$ titanium alloys. In addition, this indicates that the crack initiation life is not a negligible parameter in the surface fracture regime.

The derived internal crack propagation rate has a similar order of magnitude with that of steel reported by many other researchers $\left(\approx 10^{-11}-10^{-13} \mathrm{~m} /\right.$ cycles $)[34,35]$. In addition, the lattice constant of the internal fracture regime of the $\beta$ titanium alloys is listed in the diagram. Most of the derived internal crack propagation rate was below the lattice constant regardless of the crack initiation life. Previous studies have reported that the internal fatigue crack presumably exhibits an intermittent behavior. This indicates that it cannot propagate continuously, and its propagation rate is below the lattice constant $[13,14]$. Therefore, the derived internal crack propagation rate can be considered reasonable.

Furthermore, through X-ray CT observation of the internal fractures in Ti-6Al-4V, previous studies have reported that the propagation rate of internal cracks reached $10^{-14} \mathrm{~m} / \mathrm{cycles}$ with two orders of variation at a lower $\Delta K$ region around 2-3 $\mathrm{MPa} \sqrt{ } \mathrm{m}[36,37]$. According to Figure 15, the difference in the estimated crack propagation rate between the $90 \%$ and $0 \%$ initiation life was only one order of magnitude. Meanwhile, at a particular crack propagation rate, the deviation of the $\Delta K$ between $90 \%$ and $0 \%$ initiation life was merely less than $0.2 \mathrm{MPa} \sqrt{ } \mathrm{m}$. This indicates that the deviation of the crack propagation rate due to various crack initiation life has no significant effect on the internal fracture. Namely, the crack initiation life is negligible to estimate the $d a / d N-\Delta K$ relation of internal cracks when the Tanaka-Akiniwa model is employed. Mathematically, the cliffy gradient in the $d a / d N-\Delta K$ curve (i.e., a large value of the material constant $m$ ) of the internal fracture also represents the different significance of the crack initiation life on the surface and internal fractures. As a conclusion, the crack initiation life has a significant effect on the derivation of the material constants in the surface fracture regime. However, it has a relatively negligible effect in the internal fracture regime.

\section{Conclusions}

To clarify the behavior of the internal fatigue cracks on $\beta$ titanium alloys, fatigue tests and fractography were performed on a Ti-22V-4Al alloy, and the following conclusions were drawn:

1. The $S-N$ curves under negative stress ratios exhibit a step-wise shape with a fatigue limit of the surface fracture. However, under a positive stress ratio, the fatigue limit of the surface fracture becomes less remarkable, and the $S-N$ curve exhibited an asymptote shape.

2. The concepts of major and minor facet(s) and the classification of the facet bonding patterns were established to differentiate the various characteristics of the multiple facets and to describe their distinct growth behaviors. Both the major and minor facet(s) exhibited a $45^{\circ}$ facet angle to the fracture surfaces, indicating that they were presumably formed by slip dislocation.

3. The total facet area and major facet area are applied to the $\Delta K_{\text {ini }}-N_{e} / \sqrt{\text { area }_{\text {ini }}}$ diagram and fatigue life prediction. The effect of stress ratios mentioned in conclusion 1 was diminished by substituting the range of the applied stress. In the internal fracture regime, when the major facet area was used, the $\Delta K_{i n i}-N_{e} / \sqrt{\operatorname{area}_{i n i}}$ diagram showed a better linear relationship. In addition, there was a lower deviation in the predicted fatigue life when the major facet area was used than when the total facet area was used. These results confirm the reliability of two-step facet growth behaviors of the internal fractures. In addition, the results of the surface cracks obtained by the total facet area and major facet(s) area were all reliable, suggesting that the surface fracture was easily propagated owing to its high propagation rate regardless of the microstructural effect. 
4. Facet formation life can be omitted in both the surface and internal fracture regimes. However, the crack initiation life can only be considered negligible in the internal fracture regime, and not in the surface fracture regime, which can be attributed to the larger exponential material constant, $m$, of the internal fracture.

Author Contributions: Conceptualization and methodology, G.X. and T.N.; formal analysis, G.X.; investigation, G.X. and N.F.; resources, H.O.; writing —original draft preparation, G.X.; writingreview and editing, T.N., N.F., and H.O.; supervision, T.N. and K.T.; funding acquisition, T.N. All authors have read and agreed to the published version of the manuscript.

Funding: This research was funded by the Japan Society for the Promotion of Science, Japan, grant number: Scientific Research (A, 18H03748).

Acknowledgments: The authors express sincere appreciation to Daido Steel Co., Ltd. for providing the experimental material. This work was supported by f3 Engineering Education and Research Center, Faculty of Engineering, Hokkaido University. The authors are profoundly grateful to a graduate student at Hokkaido University, Keigo Kagaya, for his technical support to the experiment.

Conflicts of Interest: The authors declare no conflict of interest.

\section{References}

1. Kolli, R.; Devaraj, A. A review of metastable beta titanium alloys. Metals 2018, 8, 506. [CrossRef]

2. Cotton, J.D.; Briggs, R.D.; Boyer, R.R.; Tamirisakandala, S.; Russo, R. State of the art in beta titanium alloys for airframe applications. J. Miner. Mater. Mater. Soc. JOM 2015, 67, 1281-1303. [CrossRef]

3. Boyer, R.R.; Briggs, R.D. The use of $\beta$ titanium alloys in the aerospace industry. J. Mater. Eng. Perform. 2005, 14, 681-685. [CrossRef]

4. Ivasishin, O.M.; Markovsky, P.E.; Matviychuk, Y.V.; Semiatin, S.L.; Ward, C.H.; Fox, S. A comparative study of the mechanical properties of high-strength beta-titanium alloys. J. Alloys Comp. 2008, 457, 296-309. [CrossRef]

5. Marines, I.; Bin, X.; Bathias, C. An understanding of very high cycle fatigue of metals. Int. J. Fatigue 2003, 25, 1101-1107. [CrossRef]

6. Pyttel, B.; Schwerdt, D.; Berger, C. Very high cycle fatigue-Is there a fatigue limit? Int. J. Fatigue 2011, 33, 49-58. [CrossRef]

7. Tokaji, K.; Karita, H. Mean stress dependence of fatigue strength and subsurface crack initiation Ti-15Mo-5Zr-3Al alloy. Mater. Sci. Eng. A 2000, 281, 268-274. [CrossRef]

8. Tokaji, K.; Takafuji, S.; Ohya, K.; Kato, Y.; Mori, K. Fatigue behaviour of beta Ti-22V-4Al alloy subjected to surface-microstructural modification. J. Mater. Sci. 2003, 38, 1153-1159. [CrossRef]

9. Campanelli, L.C.; da Silva, P.S.C.P.; Bolfarini, C. High cycle fatigue and fracture behavior of Ti-5Al-5Mo-5V-3Cr alloy with BASCA and double aging treatments. Mater. Sci. Eng. A 2016, 658, 203-209. [CrossRef]

10. Kocan, M.; Wagner, L.; Rack, H.J. Fatigue performance of metastable $\beta$ titanium alloys: Effects of microstructure and surface finish. J. Mater. Eng. Perform. 2005, 14, 765-772. [CrossRef]

11. Huang, C.; Zhao, Y.; Xin, S.; Tan, C.; Zhou, W.; Li, Q.; Zeng, W. Effect of microstructure on high cycle fatigue behavior of Ti-5Al-5Mo-5V-3Cr-1Zr titanium alloy. Int. J. Fatigue 2017, 94, 30-40. [CrossRef]

12. Tanaka, K.; Akiniwa, Y. Fatigue crack propagation behaviour derived from S-N data in very high cycle regime. Fatigue Fract. Eng. Mater. Struct. 2002, 25, 775-784. [CrossRef]

13. Furuya, Y. Small internal fatigue crack growth rate measured by beach marks. Mater. Sci. Eng. A 2016, 678, 260-266. [CrossRef]

14. Furuya, Y. A new model for predicting the gigacycle fatigue strength of high-strength steels. Mater. Sci. Eng. A 2019, 743, 445-452. [CrossRef]

15. Shiozawa, K.; Kuroda, Y.; Nishino, S. Effect of stress ratio on subsurface fatigue crack initiation behavior of beta-type titanium alloy. Trans. Jpn. Soc. Mech. Eng. Ser. A 1998, 64, 2528-2535. [CrossRef]

16. Pan, X.; Su, H.; Sun, C.; Hong, Y. The behavior of crack initiation and early growth in high-cycle and very-high-cycle fatigue regimes for a titanium alloy. Int. J. Fatigue 2018, 115, 67-78. [CrossRef]

17. Liu, X.; Sun, C.; Hong, Y. Faceted crack initiation characteristics for high-cycle and very-high-cycle fatigue of a titanium alloy under different stress ratios. Int. J. Fatigue 2016, 92, 434-441. [CrossRef]

18. Daido Steel Co., Ltd. DAT51 (High Strength $\beta$-Titanium Alloy) with Improved Press Workability. Available online: https:/ / www.daido.co.jp/en/products/titanium/strength/index.html (accessed on 19 December 2020).

19. Fukui, S.; Ohtakara, Y.; Suzuki, A. Properties of a beta type new titanium alloy Ti-22V-4Al. DENKI-SEIKO 1986, 57, 303-317. (In Japanese) [CrossRef]

20. Schneider, C.A.; Rasband, W.S.; Eliceiri, K.W. NIH image to ImageJ: 25 years of image analysis. Nat. Methods 2012, 9, 671-675. [CrossRef]

21. Santhosh, R.; Geetha, M.; Saxena, V.K.; Rao, M.N. Effect of duplex aging on microstructure and mechanical behavior of beta titanium alloy Ti-15V-3Cr-3Al-3Sn under unidirectional and cyclic loading conditions. Int. J. Fatigue 2015, 73, 88-97. [CrossRef] 
22. Uematsu, Y.; Kakiuchi, T.; Hattori, K. EBSD-assisted fractography of sub-surface fatigue crack initiation mechanism in the ultrasonic-shot-peened ßeta-type titanium alloy. Fatigue Fract. Eng. Mater. Struct. 2018, 41, 2239-2248. [CrossRef]

23. Jha, S.K.; Szczepanski, C.J.; Golden, P.J.; Porter, W.J., III; John, R. Characterization of fatigue crack-initiation facets in relation to lifetime variability in Ti-6Al-4V. Int. J. Fatigue 2012, 42, 248-257. [CrossRef]

24. Oguma, H.; Nakamura, T. Fatigue crack propagation properties of Ti-6Al-4V in vacuum environments. Int. J. Fatigue 2013, 50, 89-93. [CrossRef]

25. Tokaji, K.; Ohya, K.; Kariya, H. Effect of grain size on fatigue strength and subsurface crack initiation in beta Ti-22V-4Al alloy. J. Soc. Mater. Sci. Jpn. 2000, 49, 994-1001. [CrossRef]

26. Tokaji, K.; Ohya, K.; Kariya, H. Effects of grain size and aging conditions on fatigue crack propagation behavior in beta Ti-22V-4Al alloy. Tetsu-to-Hagane 2000, 86, 769-776. [CrossRef]

27. Tanaka, K.; Akiniwa, Y.; Nakai, Y.; Wei, R.P. Modelling of small fatigue crack growth interacting with grain boundary. Eng. Fract. Mech. 1986, 24, 803-819. [CrossRef]

28. Lankford, J. The growth of small fatigue cracks in 7075-T6 aluminum. Fatigue Fract. Eng. Mater. Struct. 1982, 5, 233-248. [CrossRef]

29. Zhai, T.; Wilkinson, A.J.; Martin, J.W. A crystallographic mechanism for fatigue crack propagation through grain boundaries. Acta Mater. 2000, 48, 4917-4927. [CrossRef]

30. Paris, P.; Erdogan, F. A critical analysis of crack propagation laws. J. Basic Eng. 1963, 85, 528-533. [CrossRef]

31. Omata, S. Evaluation of fatigue properties in the ultra-high-cycle regime of steels for crankshafts based on crack propagation characteristics. In Proceedings of the Third International Conference on Very High Cycle Fatigue (VHCF-3), Kyoto, Japan, 16-19 September 2004; The Society of Materials Science: Kyoto, Japan, 2004; p. 306.

32. Murakami, Y.; Kodama, S.; Konuma, S. Quantitative evaluation of effects of non- metallic inclusions on fatigue strength of high strength steels. I: Basic fatigue mechanism and evaluation of correlation between the fatigue fracture stress and the size and location of non-metallic inclusions. Int. J. Fatigue 1989, 11, 291-298. [CrossRef]

33. Yoshinaka, F.; Nakamura, T.; Takaku, K.; Shiozawa, D.; Nakai, Y.; Uesugi, K. Observation of the initial process of internal fracture in very high cycle fatigue in Ti-6Al-4V by synchrotron radiation $\mu \mathrm{CT}$ imaging. Trans. JSME 2017, 83, 1700104. (In Japanese)

34. Stanzl-Tschegg, S.; Schönbauer, B. Near-threshold fatigue crack propagation and internal cracks in steel. Procedia Eng. 2010, 2, 1547-1555. [CrossRef]

35. Hong, Y.; Lei, Z.; Sun, C.; Zhao, A. Propensities of crack interior initiation and early growth for very-high-cycle fatigue of high strength steels. Int. J. Fatigue 2014, 58, 144-151. [CrossRef]

36. Yoshinaka, F.; Nakamura, T.; Nakayama, S.; Shiozawa, D.; Nakai, Y.; Uesugi, K. Non-destructive observation of internal fatigue crack growth in Ti-6Al-4V by using synchrotron radiation $\mu \mathrm{CT}$ imaging. Int. J. Fatigue 2016, 93, 397-405. [CrossRef]

37. Yoshinaka, F.; Nakamura, T.; Takeuchi, A.; Uesugi, M.; Uesugi, K. Initiation and growth behavior of small internal fatigue cracks in Ti-6Al-4V via synchrotron radiation microcomputed tomography. Fatigue Fract. Eng. Mater. Struct. 2019, 42, $2093-2105$. [CrossRef] 